\title{
Employee perception of work stress in a large construction company in Australia
}

\author{
Teck Heng Benson, Lim $^{1}$, and Adam Perica ${ }^{1}$ \\ ${ }^{1}$ Construction Management and Property, Faculty of Built Environment, University of New South Wales UNSW, Sydney, Australia
}

\begin{abstract}
Managing stress effectively is touted to be a key determinant of increased performance. It is however believed that individuals perceive and cope with stress differently. This thus makes stress management more complicated in construction. The aim of this research is to investigate the perceived work stress of construction employees by examining how perceived stress vary across employees and the perceived stress correlate with employee performance. In addressing these, an online questionnaire survey of 187 construction employees was undertaken, and data were analysed using the relative prevalence indexing method, ANOVA and Pearson correlation tests. The overall results show that poor work-life balance and work overloads are the major negative perceived stressors for construction professionals. Furthermore, there were differences in the perceived stress among cadets, operational staff, middle and top management. Lastly, the findings reveal the interpersonal and organisational climate have strong association with employee performance. In conclusion, the findings shed lights on the spectrum of work stress underling employee performance and how different cohorts of employees perceive and experience work stress.
\end{abstract}

\section{INTRODUCTION}

In construction, workplace stress is often reported as the key cause to adverse reactions that are detrimental to employees' health and performance (e.g., [1], [2]). Hitherto, a considerable amount of research has documented a list of factors that could attribute to workplace stress: a toxic work environment [2], negative workload [2], role ambiguity [1], lack of autonomy [1], bullying and harassment [3], career development barriers [4] and organisational climate [5]. As suggested by Lingard et al. [6], unlike other organisational assets, employees' needs and mental wellbeing cannot be overlooked as their capabilities cannot be easily replicated. It is critical for management to create a positive work environment, devoid of distress, for higher employee productivity and improved organisational performance.

The aim of this paper is to investigate the perceived work stress of construction professionals, by specifically examining how the perceived work stress varies across different roles; and how the perceived stress correlate with employee performance. By knowing these, company management could develop better targeted stress management strategies for different cohorts of employees.

\subsection{LITERATURE REVIEW}

According to Leung et al. [2], workplace stressors in construction could be classified into five categorises. Personal stressors are specific to individual employees' attitude toward work-life balance. Interpersonal stressors refer to the relationships with supervisors, colleagues, sub-contractors or clients. Task stressors relate the demands of a job. Organisational stressors relate to an organisation's decision-making processes. Lastly, physical stressors refer to the work environment that each employee is exposed to.

Over the past decades, a considerable amount of research has been done to explore how construction professionals and workers perceive their work stress across different countries. For example, Loosemore and Waters' [4] analysis of the stress perception of 190 male and female construction professionals in Australia have shown that excessive workload and low salary are the key stressors for men and women, respectively. Their findings further point out that male managers perceived 'implications of mistakes' and 'conflict or confrontational situations' as the primary workplace stressors, while their female counterparts pointed to the low job control and work overload. Similarly, Lingard and Francis [7] found that there exists a strong association between job scheduled irregularity, excessive working hours and emotional exhaustion in their sample of 231 male construction professionals, managers and administrators. Later, Lingard et al.'s [1] research further showecased that there is a strong negative association between employees' quality of life and their weekly hours worked, and that when employees worked consistently for more than 25-hour overtime per week, they were very likely to feel stressed, overloaded. More recently, Sunindijo and Kamardeen's [3] research on work stress in the Australian construction industry have

\footnotetext{
* Corresponding author: b.lim@unsw.edu.au
} 
shown that both men and female construction professionals shared the top 10 stressors, with time pressure, excessive workload, long work hours and unpleasant work environment being the most critical issues.

\subsection{RESEARCH DESIGN AND METHODS}

In this study, an online survey questionnaire was designed based on the stressor- and performance- related measurement items proposed by Leung et al. [2, 5]. The questionnaire was pretested, validated and amended before being distributed to employees in an Australian construction and civil engineering company. In the first section, respondents were required to provide their background information (i.e., age, years of experience, average weekly hour worked and position). For subsequent sections, the respondents were requested to rate statements, regarding to: personal/ interpersonal stressors; task stressors; organizational stressors; physical stressors; and performance, based on a sevenpoint Likert Scale, ranging from 1 (strongly disagree) to 7 (strongly agree). Of these, some items had been worded reversely to increase the validity of questionnaire responses (e.g., TS2, TS3, TS4, OS1, OS2, PS1 and PS2). Table 1 summarises the measurement items used in this study.

For data analysis, the relative prevalence indexing (RPI) method, ANOVA and Pearson Correlation tests were conducted. The RPI method was preferred over the arithmetic average method because the former can derive relative indices within the range of $0-1$ for each item and therefore enable researchers to undertake relative comparisons of items relating to the different types of stressors. This is an outcome that could be not achieved by directly comparing the arithmetic average of each items considering that items could have different maximum mean values (see [8]). The ANOVA test was conducted to determine if there are significant differences in the perceived stress among cadets, operational staff and middle and top management. Lastly, the Pearson Correlation test was undertaken to examine the relationship between perceived stress and performance of employees. For ease of interpretation, we had adopted Hinkle et al.'s [9] guideline to determine the magnitude of association.

Table 1. Measurement items

\begin{tabular}{|c|c|}
\hline \multicolumn{2}{|c|}{ Code $\quad$ Description } \\
\hline \multicolumn{2}{|c|}{ Personal Stressors } \\
\hline PS1 & $\begin{array}{l}\text { My personal relationships are not affected by my work } \\
\text { commitments }\end{array}$ \\
\hline PS2 & $\begin{array}{l}\text { My role requirements allow me plenty of time to spend } \\
\text { with my family }\end{array}$ \\
\hline PS3 & My role is flexible as long as I work my required hours \\
\hline \multicolumn{2}{|c|}{ Interpersonal Stressors } \\
\hline IP1 & I have a good relationship with my colleagues \\
\hline IP2 & es are trustworthy and personable \\
\hline IP3 & $\begin{array}{l}\text { My supervisor gives me recognition when I do a good } \\
\text { job }\end{array}$ \\
\hline IP4 & $\begin{array}{l}\text { I feel comfortable talking to my supervisor when I make } \\
\text { a mistake }\end{array}$ \\
\hline IP5 & $\begin{array}{l}\text { I feel comfortable requesting and using my leave } \\
\text { entitlements }\end{array}$ \\
\hline
\end{tabular}

Task Stressors

TS1 I am in control of my workload

TS2 I often need to shorten or skip my lunch breaks to stay on top of my work demands

TS3 Sometimes I must work from home or on my annual leave to stay on top of my work

TS4 I work more hours than most people I know

TS5 I rarely need to work overtime

TS6 I am happy with the hours I work each week

TS7 My job responsibilities are often vague or unclear

TS8 I am often caught between conflicting demands from different supervisors

Organisational Stressors

OS1 Small matters often require referral to senior management for decision making

OS2 Most decisions I make need my supervisors' approval

OS3 I am often asked to complete a job differently to how I prefer

OS4 I am often required to carry out complicated procedures that do not make sense to me

OS5 I have control over when I start and finish work

OS6 I feel stable within my role in the company

OS7 I feel there are promotional opportunities available to me throughout my career with the company

OS8 My company provides mentoring, peer support and other training to support my professional development

Physical Stressors

PS1 My office is overcrowded

PS2 My office is too noisy

PS3 The temperature of my office is uncomfortable

PS4 The safety equipment where I work is in good condition

PS5 The safety equipment where I work is regularly checked

PS6 I am satisfied with the overall levels of health and safety implemented by my company

Performance

P1 I always meet my required deadlines

P2 I always meet the quality requirements of my tasks

P3 My planned schedules of programmes are effective

P4 I am a good communicator

P5 I feel confident in developing good relationships with others

P6 People enjoy working with me

P7 I believe in my company's goals and objectives

P8 I work hard to achieve the objectives of my role

P9 I have no intentions of leaving my company

For the data collection, 483 employees were invited to complete the online questionnaire survey. After three weeks, a total of 187 valid and complete responses were collected. Generally, about two-fifth of the 187 respondents were from middle management (38\%), aged at least 40 years $(47 \%)$ and had more than 16 years of working experience $(46 \%)$ in the construction industry. More than $50 \%$ of them had worked about 50-60 hours per week on average.

\subsection{RESULTS AND DISCUSSION}

Table 2 summarises the perceived work stress among cadets, operational staff, middle and top management. The overall results reveal that most participants perceived the "Interpersonal Stressors (IS)" and "Physical Stressors (PYS) as quite positive, with the corresponding overall RPIs of 0.79 and 0.78 . On the other hand, it appears that the "Task Stressors (TS)" and "Personal Stressors (PS)" had caused distress to employees, with the corresponding overall RPIs ranging 
from 0.45 to 0.52 . These collectively add weight to the current debate that poor work life balance and work overload are the key negative stressors for construction professionals [1]. Our findings also tend to agree with Loosemore and Lim's [10] conclusion that middle management were the main victims of workplace injustice; as they were found to have suffered excessively poor work-life balance and task uncertainty comparing to other groups of employees.

Table 2 Perceived stress among different employees

\begin{tabular}{|c|c|c|c|c|c|}
\hline \multirow[b]{2}{*}{ CODE } & \multicolumn{5}{|c|}{ Roles } \\
\hline & Cadet & O.S. & M. M. & T.M & F statistic \\
\hline$\overline{\text { PS1 }}$ & $4.03(0.57)$ & $3.41(0.48)$ & $3.02(0.43)$ & $3.2(0.45)$ & 2.528 \\
\hline PS2 & $4.15(0.59)$ & $2.9(0.41)$ & $2.59(0.37)$ & $3.5(0.5)$ & $6.999 *$ \\
\hline PS3 & $3.69(0.52)$ & $3.07(0.43)$ & $2.85(0.40)$ & $3.5(0.5)$ & 1.719 \\
\hline IP1 & $6.03(0.86)$ & $5.94(0.84)$ & $5.87(0.83)$ & $6.05(0.86)$ & 0.477 \\
\hline IP2 & $5.92(0.84)$ & $5.72(0.81)$ & $5.74(0.82)$ & $6.05(0.86)$ & 1.177 \\
\hline IP3 & $5(0.71)$ & $4.6(0.65)$ & $4.67(0.66)$ & $4.6(0.65)$ & 0.445 \\
\hline IP4 & $5.61(0.80)$ & $5.28(0.75)$ & $5.43(0.77)$ & $5.55(0.79)$ & 0.678 \\
\hline IP5 & $4.84(0.69)$ & $5.3(0.75)$ & $5.25(0.75)$ & $5.5(0.78)$ & 0.758 \\
\hline TS1 & $5.07(0.72)$ & $4.57(0.65)$ & $4.52(0.64)$ & $4.55(0.65)$ & 0.84 \\
\hline TS2 & $3.30(0.47)$ & $2.87(0.41)$ & $2.45(0.35)$ & $2.2(0.31)$ & $3.435 * *$ \\
\hline TS3 & $4.84(0.69)$ & $3.92(0.56)$ & $3.07(0.43)$ & $2.75(0.39)$ & $9.428 * *$ \\
\hline TS4 & $3.69(0.52)$ & $2.27(0.32)$ & $2.11(0.30)$ & $2.75(0.39)$ & $10.68 * *$ \\
\hline TS5 & $3.30(0.47)$ & $2.35(0.33)$ & $1.94(0.27)$ & $2.4(0.34)$ & $6.535 * *$ \\
\hline TS6 & $4(0.57)$ & $3.48(0.49)$ & $3.11(0.44)$ & $4.3(0.61)$ & $3.817^{*}$ \\
\hline TS7 & $4.65(0.66)$ & $4.72(0.67)$ & $4.95(0.70)$ & $4.9(0.7)$ & 0.379 \\
\hline TS8 & $5.15(0.73)$ & $4.47(0.63)$ & $4.25(0.60)$ & $4.3(0.61)$ & 1.896 \\
\hline OS1 & $4(0.57)$ & $4.61(0.65)$ & $5.05(0.72)$ & $4.35(0.62)$ & $3.124 *$ \\
\hline OS2 & $2.61(0.37)$ & $4.07(0.58)$ & $5.07(0.72)$ & $4.75(0.67)$ & $17.56^{* *}$ \\
\hline OS3 & $4.73(0.67)$ & $4.7(0.67)$ & $4.76(0.68)$ & $4.75(0.67)$ & 0.022 \\
\hline OS4 & $4.76(0.68)$ & $5.14(0.73)$ & $5.11(0.73)$ & $4.75(0.67)$ & 0.771 \\
\hline OS5 & $3.5(0.5)$ & $3.98(0.56)$ & $3.56(0.50)$ & $4.9(0.7)$ & $3.596^{*}$ \\
\hline OS6 & $5.03(0.71)$ & $5.11(0.73)$ & $5.14(0.73)$ & $5.55(0.79)$ & 0.587 \\
\hline OS7 & $4.19(0.59)$ & $4.11(0.58)$ & $4.04(0$ & $4.8(0.68)$ & 1.003 \\
\hline OS8 & $4.07(0.58)$ & $4.28(0.61)$ & 3.71( & $4.15(0.59)$ & 1.271 \\
\hline PYS1 & $5.84(0.83)$ & $5.21(0.74)$ & $5.25(0.75)$ & $4.95(0.70)$ & 2.045 \\
\hline PYS2 & $5.03(0.71)$ & $4.77(0.68)$ & $4.61(0.65)$ & $4.9(0.7)$ & 0.47 \\
\hline PYS3 & $4.84(0.69)$ & $4.78(0.68)$ & $4.85(0.69)$ & $5.2(0.74)$ & 0.361 \\
\hline PYS4 & $5.76(0.82)$ & $5.85(0.83)$ & $6.01(0.85)$ & $5.8(0.82)$ & 0.674 \\
\hline PYS5 & $5.65(0.80)$ & $5.91(0.84)$ & $6.04(0.86)$ & $6.1(0.87)$ & 1.242 \\
\hline PYS6 & $5.73(0.81)$ & $5.91(0.84)$ & $5.97(0.85)$ & $6.1(0.87)$ & 0.619 \\
\hline
\end{tabular}

It is notable that there were significant differences in the perception of PS2, TS2, TS3, TS4, TS5, TS6, OS1, OS2 and OS5 among employees, with the F statistics ranging from 3.124 to 10.68 . Of these, the post hoc test results reveal that cadet employees had significantly more time than their operational and middle management counterparts in spending time with their family (PS2).

Our findings further indicate that cadet employees were significantly less stressful than other employees in performing their tasks; considering that they were less likely to: shorten or skip their lunch to stay on top of their work (TS2); work from home or during annual leave (TS3); and work for a longer hour (TS4) and overtime (TS5). This could partially be explained to the supportive role of cadets to senior and more experienced employees. Furthermore, we found operational staff were significantly less likely to work from home or during annual leave than middle and top management did. This thus could indicate that the higher the position an employee hold, the more likely she or he would need to work from home or during annual leave. Interestingly, the post hoc test results further reveal that middle management were significantly less content than top management in terms of their working hour (TS6). An overall picture that emerges from here is that middle management could have spent more time than top management in managing subordinates and aligning project requirements and organisational priorities. This tends to agree with Caye et al.'s [11] assertions that middle management is the link between top management and team members, and that if top management set aspirations and strategy, they would then be responsible to translate those strategies into business plans and communicate them with other employees.

Adding to the above, the results suggest that cadet employees were significantly more inclined to experience organisational stress than the other employees; as they lacked autonomy and control over their work (OS5), and often required to seek approval from their supervisors (OS1 and OS2). Further to this, there seems to be a spill-over effect of deficiency of autonomy between operational staff, and middle and top management. Particularly, it is found that operational staff were more inclined to consult their supervisors for decision making than middle management required (OS2), while the latter had lesser control than top management in controlling work schedule. Interestingly, this further point to the "sandwiched" role of middle management.

Table 3 summarises the correlations between employees' perceived work stress and performance. It is notable that most of the stressor-related items have moderately strong positive correlation with employees' trust with their company (P7). Overall, the results reveal that employees are more likely to trust their employers, when there exists a positive, friendly and safe organisational climate where employees are trustworthy and encouraged to interact among each other, and have been given opportunities for career progression. These results tend to support McCarthy et al.'s [12] claim that employees, who experience high levels of organisational support, are more likely to portray high job satisfaction, and low turnover intentions. This further helps explaining the low positive correlation between P9 and OS8, pointing that employees are less likely to think of leaving the company when they had been given proper guidance and sufficient training for their professional development. This also tends to support Lim and Ling's [13] findings that effective competence development strategies could help improving employees' soft skills and gaining their behavioural commitment.

Turning to their task performance, we found that when employees can control their overload (TS1) and receive less conflicting but challenging work orders from their supervisors (TS8 and OS3), they are more likely to be efficient (P1) and effective (P3). This adds weight to Crane's [14] conclusion that task autonomy and interest play a key role in dictating an individual's goal setting 
behaviour and overall performance. Lastly, we found that peer relations (IP1) are positively correlated with individuals' ability and confidence of building up social relationships (P5) and developing a positive and interactive work environment (P6). This tends to support Lim and Ling's [13] assertion that effective intraorganisational relationship management is a key driver in promoting learning culture and a 'no-blame' attitude among employees.

Table 3 Correlations between perceived stress and performance

\begin{tabular}{|c|c|c|c|c|c|c|c|c|c|}
\hline Items & P1 & P2 & P3 & P4 & P5 & P6 & P7 & P8 & P9 \\
\hline$\overline{\text { PS1 }}$ & & .219 & .170 & & & & & & \\
\hline PS2 & & & & & & & .218 & & .203 \\
\hline IP1 & & .193 & & .259 & .508 & .429 & .333 & .160 & .152 \\
\hline IP2 & & & & & .295 & .318 & .342 & & .193 \\
\hline IP3 & & & & & .152 & .156 & .440 & & .222 \\
\hline IP4 & .208 & .150 & .285 & .202 & .254 & .198 & .454 & & .171 \\
\hline IP5 & & & .244 & & & & .278 & & \\
\hline TS1 & .300 & 286 & .387 & .152 & & & .231 & & .215 \\
\hline TS2 & & & & & & & .175 & -.212 & \\
\hline TS3 & & & & & & & .227 & -.160 & .162 \\
\hline TS4 & & & & & & & .179 & & .161 \\
\hline TS5 & .239 & .178 & .149 & & & & .237 & & .223 \\
\hline TS6 & & & .159 & & & & .229 & & .209 \\
\hline TS7 & & & & & & & .209 & & .192 \\
\hline TS8 & .309 & .148 & .198 & .162 & .156 & & .202 & & \\
\hline OS1 & & & & & & & .198 & & \\
\hline OS2 & & -.169 & & & & & & & \\
\hline OS3 & .353 & & .224 & & .168 & .156 & .228 & & \\
\hline OS4 & .183 & & & & & & .204 & & \\
\hline OS5 & & & & & & & .164 & & .162 \\
\hline OS6 & & & .235 & & .201 & .156 & .351 & & .221 \\
\hline OS7 & & & .145 & & & & .344 & & .294 \\
\hline OS8 & & & .214 & & .175 & .210 & .403 & & .352 \\
\hline PYS1 & & & & & & & .172 & & \\
\hline PYS2 & & & .166 & & & & .248 & & .174 \\
\hline PYS3 & & & & & & & .229 & & \\
\hline PYS4 & & & .152 & .192 & .164 & .153 & .273 & & \\
\hline PYS5 & & .168 & .223 & .232 & .196 & .244 & .335 & & \\
\hline PYS6 & & .179 & .224 & .225 & .177 & .246 & .333 & & .148 \\
\hline
\end{tabular}

\subsection{CONCLUSION}

This exploratory research aimed to investigate the perceived work stress of 187 employees in a large construction company. The overall findings show that employees were more disposed to be distressed by personal work-life imbalance and task uncertainty. Particularly, the findings highlight the plight of middle management, who appear to consistently suffer the highest levels of work stress. Furthermore, the findings shed light on the key function of interpersonal climate and organisational supports in stimulating or undermining employees' performance.

Lastly, it is acknowledged that there are limitations in this study and the findings are indicative and not conclusive. First, the sample size of 187 is small and not representative. Particularly, data was collected from a single company. However, the findings could further add to the existing knowledge of stress management for future studies. Further analyses (such as predictive modelling) should be conducted to examine the multilevel effect of perceived work stress on performance. A cross-cultural investigation of work stress should also be considered in future studies

\subsection{REFERENCES}

[1] Lingard H., Francis. V., and Turner. M., Work-life strategies in the Australian construction industry: Implementation issues in a dynamic project-based work environment. Int. Journal of Project Management, 30 (2012), 282-295.

[2] Leung, M., Chan, I., and Cooper, C., Stress management in the construction industry. John Wiley \& Sons, (2015).

[3] Sunindijo, R. Y. and Kamardeen, I., Work stress is a threat to gender diversity in the construction industry. Journal of Construction Engineering and Management, 143 (2017).

[4] Loosemore, M. and Waters, T., Gender differences in occupational stress among professionals in the construction industry. Journal of Management in Engineering, 20 (2004), 126-132.

[5] Leung, M. Y., Skitmore, M. and Chan, Y. S., Subjective and objective stress in construction cost estimation. Construction Management and Economics, 25 (2007), 1063- 1075.

[6] Lingard. H. Brown. K. Bradley. L. and Bailey. C. Townsend. K., Improving employees work life balance in the construction industry: Project alliance case study. Journal of Construction Engineering and management, 133 (2007), 807-815.

[7] Lingard H. and Francis. V., Managing work-life balance in construction. Taylor and Francis. New York, (2009).

[8] Loosemore, M. and B.T.H Lim, Inter-organizational unfairness in the construction industry. Construction Management and Economics, 33 (2015), 310-326.

[9] Hinkle D.E, Wiersma, W. and Jurs S.G., Applied Statistics for the Behavioral Sciences, 5th ed. Boston: Houghton Mifflin, (2003).

[10] Loosemore, M. and Lim B.T.H., Intra-organisational injustice in the construction industry. Engineering, Construction and Architectural Management, 23 (2016), 428-447.

[11] Caye, J.M., Strack, R. Orlander, P., Kilmann, J., Espinosa, E.G., Francoeur, F. and Haen, P. Creating a New Deal for Middle Management: Empowering a Neglected but Critical Group. Available at https://www.bcg.com/documents/file52425.pdf, (2010)

[12] McCarthy, A., Darcy, C. and Grady, G., Work life balance policy and practice: understanding line Manager attitudes and behaviours. Human Resources Management Review, 20 (2010), 158167.

[13] Lim B.T.H. and Ling F.Y.Y., Contractors' human resource development practices and their effects on employee soft skills. Architectural Science Review, 54 (2011), 232-24.

[14] Crane, M. E., The effects of task autonomy and task interest on goal-setting behavior and task performance. ETD Archive, Paper 476, (2012). 